\title{
SPOC-based Flipped Learning Model Applied in Interpreting Teaching
}

\author{
https://doi.org/10.3991/ijet.v15i17.14581 \\ Chen Juan \\ Zhejiang Wanli University, Ningbo, China \\ wmjcj@163.com
}

\begin{abstract}
It is of great importance to construct an effective learning model in the information age. This paper aims to establish a SPOC-based flipped learning model and discuss its effectiveness when it is combined with off-line teaching of interpreting course. Following a questionnaire and data analysis from February to July in 2019, it is concluded that the SPOC-based flipped learning serves as an effective learning model which creates an interactive learning environment for students, cultivate students' autonomous learning efficiency and ability, and enables teachers to supervise and evaluate students' learning habits and effects during the whole process, which, in return, helps to improve the teaching design constantly.
\end{abstract}

Keywords—SPOC, flipped learning, interpreting teaching.

\section{$1 \quad$ Introduction}

In recent years, information technology and on-line open resources are increasingly integrated into Chinese foreign language teaching, thus resulting into new forms of learning. The NMC Horizon Report: 2013 anticipated that mobile learning will become the mainstream teaching model in the information age [1]. However, students with less autonomous learning motivation and no guidance from teachers can possibly be drown by the massive on-line resources and get half the result with twice the effort. Thus, in information age, to some degree, teaching is to guide students to find their suitable ways to learn by themselves. Domestic scholars hold the similar view that blended learning, combining the advantages of face-to-face classroom and E-learning classroom, is a significant research area in foreign language teaching reform [2].

Following the wide usage of on-line learning resources and platforms, such as MOOC, SPOC, Rain classroom, etc. the learning environment of interpreting has changed accordingly. Wang Honglin, a Chinese scholar in interpreting study, states that with regards to characteristics of interpreting education in AI era and problems existing in contemporary interpreting education, including emphasizing teaching while neglecting learning, as well as separation of learning and interpreting practice, the construction of a deep flipped interpreting learning model is crucial [3]. Actually, the advancing of interpreting technologies has affected various aspects of interpreting practice, including interpreting modes, interpreter's competence, and the professionalization of 
interpreting [4]. Thus, this paper aims to study the flipped learning model based on SPOC in college interpreting teaching, in order to strengthen the efficiency and effectiveness of students' autonomous learning.

\section{State of the Art}

Flipped learning is derived from flipped classroom. A flipped classroom gives teachers the flexibility to meet the learning needs of all their students, and it gives students the flexibility to have their needs met in multiple ways. By doing so, it creates a classroom that is truly student-centered [5]. However, a flipped classroom can, but does not necessarily, lead to flipped learning. In other words, a flipped classroom is meaningful only if it does help to improve the effect of students' learning. Therefore, in order to put learning at the center position, Sams \& Bergmann furtherly clarified the concept of flipped learning. Flipped learning helps teachers move away from direct instruction as their primary teaching tool toward a more student-centered approach [5]. According to the Flipped Learning Network (2016), flipped learning is a pedagogical approach in which direct instruction moves from the group learning space to the individual learning space, and the resulting group space is transformed into a dynamic, interactive learning environment where the educator guides students as they apply concepts and engage creatively in the subject matter [6].

Ever since the concept was put forward, a lot of scholars try to integrate flipped learning as one of the strategies into blended teaching that combines on-line platforms and resources with off-line learning activities, in order to uplift the effect of students' learning. Gao [7] studied the effect of SPOC flipped classroom learning based on MOOC platform, and concluded that the factors that affect the learning effect are student factors, learning experiences and learning methods. Shi et al. [8] investigated the learning willingness in SPOC flipped class of the undergraduate in an engineering university in the form of questionnaire survey, and found that students have a strong willingness to SPOC flipped class learning, and this method can give more autonomy to learning and improving their own learning interests and effectiveness. Mona Lundin et al. [9] stated, "for realising the flipped or inverted classroom approach, social media has become an important platform for sharing educational resources in the form of blog posts, YouTube videos or other media through social networking sites".

Likewise, the new generation of Information Technology, represented by the Internet, artificial intelligence and big data, is changing the way we do interpreting, bringing unprecedented opportunities and challenges to interpreter education [10]. Actually, some scholars have tried to analyze the on-going changes in interpreting learning or teaching, such as the learning resources, learning environment, teaching models, or teaching tools, etc. Dohun Kim [11] applies flipped learning to interpreting classroom. He argues, "while the traditional flipped model had been limited to putting video lectures online to encourage practice activities in the classroom, flipped learning has evolved to allow for diverse models and approaches that suit the needs of individual disciplines, courses and modules". 
However, traditional college interpreting teaching has many problems. Firstly, students are accustomed to passive learning, so they are inclined to receiving knowledge and information from teachers, which is harmful to build up their interpreting competence or innovative ability; secondly, in a traditionally teacher-centered classroom, inclass time is always used by teachers to give lectures on conceptual knowledge, thus leaving little time to carry on some topic discussion or in-depth skills training; thirdly, in a traditional teaching model, teachers can hardly interact with students after class, let alone providing them additional assistance or follow up their learning habits or effects.

To deal with the above-mentioned problems in college interpreting teaching, it is proposed to construct a SPOC-based flipped learning model in order to maximize the learning effects of students and improve their interpreting competence accordingly. The reason why a SPOC-based flipped learning is constructed is that the fundamental purpose of teaching is to help students to improve their learning effect. That is to say, learning is put at the center position in interpreting teaching. The innovative points include: for one thing, it is a student-centered approach which places its priority to creating a flipped learning environment for students who interact with each other and reflect on their own learning when needed. For another, SPOC platform is combined with blended teaching where diversified ways of learning are conducted by means of on-line resources sharing, video watching, individually suitable way of learning and question answering, in order to grasp the basic conceptual knowledge and skills of interpreting before the class. In-class time is dedicated to in-depth interpreting skills training with students getting fully involved in collaborative activities, and individual knowledge and competence are constructed during the process. Furthermore, after-class interactions among students and feedbacks from teachers are feasible through SPOC platform, which is meaningful to consolidate the active learning effects of students.

\section{$3 \quad$ SPOC-based Flipped Learning Model Combined with Off- line Teaching}

In this section, a flipped learning model is built based on SPOC first, and then this model is combined with off-line teaching to make the best use of flipped learning and face-to-face teaching.

\subsection{Construction of flipped learning model based on SPOC}

SPOC-based flipped learning model has its distinguishing features. Firstly, SPOC platform is a powerful support to establish a flexible learning environment for students who can choose when and where they learn. Secondly, the abundant sharing resources in SPOC platform are carefully selected, and students can make their own learning schedule under the guidance of teachers to find an individually suitable way of learning before and after the class. Thirdly, besides individual learning, collaborative learning is designed for students to fulfill some interpreting tasks because in learning, learners inevitably encounter problems, and the solution to problems usually comes from group work. The communication between co-learners facilitates learners in terms of meaning 
construction of the knowledge they are aiming for [12]. Fourthly, students are encouraged to reflect on their learning effects and to make adjustments if necessary, meanwhile, teachers can give students useful feedbacks to guide them through the whole process of learning. That is to say, flipped learning is an approach in which the conventional notion of classroom-based learning is inverted, so that students are introduced to the learning material before class, with classroom time then being used to deepen understanding through discussion with peers and problem-solving activities facilitated by teachers [13]. The SPOC-based flipped learning model is constructed as follows:

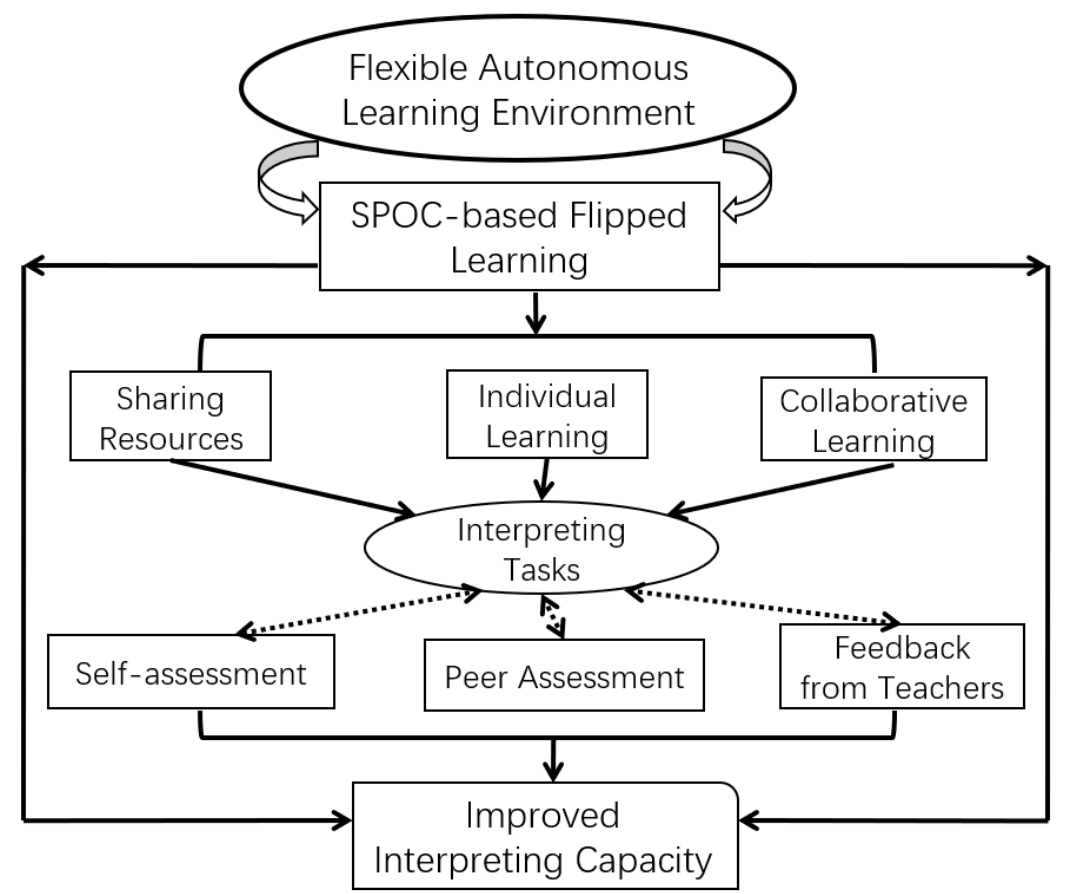

Fig. 1. SPOC-based Flipped Learning Model

From figure 1, it is clear that learning is highlighted, and all the learning procedures, including resources sharing, individual learning, and collaborative learning are taskdriven. First, SPOC platform is established to provide a flexible learning environment for students before and after the class. Second, sharing resources are selected and interpreting tasks are designed for students to carry out individual learning or collaborative learning. Finally, during the learning process, self-assessment and peer assessment are encouraged together with feedbacks from teachers, in order to finish the interpreting tasks effectively and improve students' interpreting capacity.

Flipped Learning model based on SPOC allows for diversified ways of learning, and when it is combined with off-line teaching, it is supposed to make the best out of faceto-face teaching and flipped learning. 


\section{2 $\quad$ SPOC-based flipped learning model blended with off-line teaching}

The author has employed the SPOC-based flipped learning model to teach the course of interpreting in a Chinese university. After years of practice and constant improvement in our university, some favorable outcomes have been achieved, and the specific practice of blending this model with the off-line teaching process is illustrated in the following Figure 2.

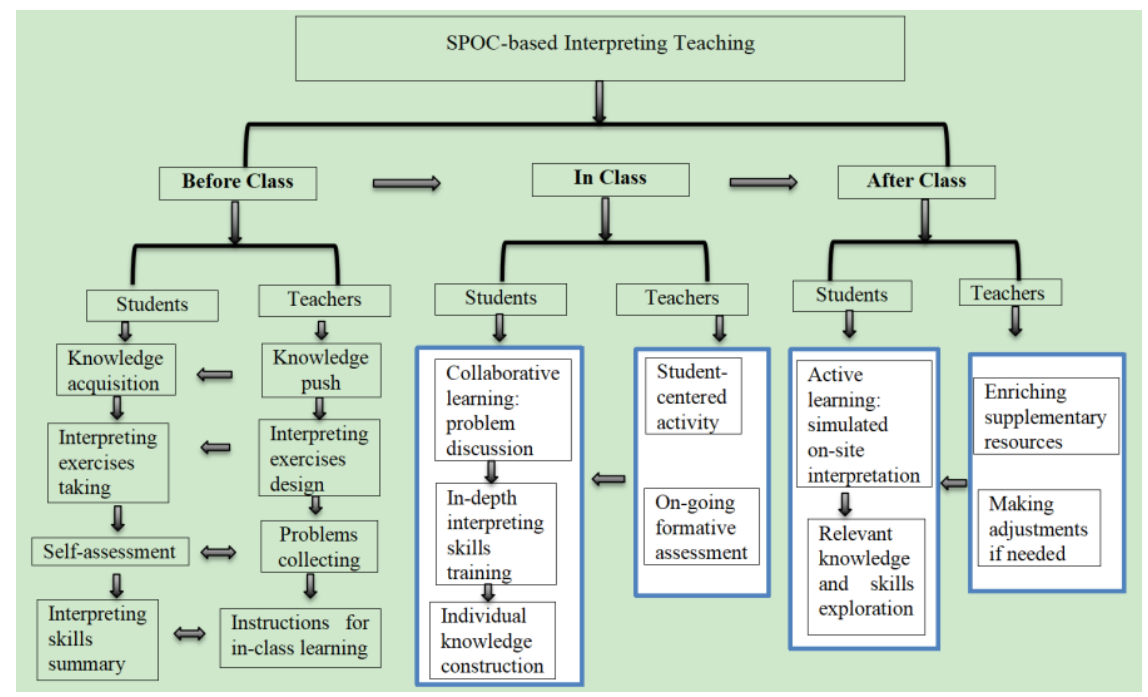

Fig. 2. SPOC-based Interpreting Teaching

From figure 2, the SPOC-based interpreting teaching is consisted of three stages, namely, before class, in class and after class. However, no matter in what stage, all the teaching design and teachers' efforts are student-centered.

Firstly, before the class, teachers open on-line classroom on SPOC platform with eight different sections, namely, "video watching," "resources sharing," "exercise before the class," "questions and answers," "exercise after the class," "quiz for skills training," "group chat," and "reflective assessment." Then, teachers upload meticulously selected sharing resources, mini-lecture videos, exercises and quizzes for interpreting skills, as well as monitor and evaluate students' learning behaviors during the process.

Meanwhile, Students first make their own learning schedule under the guidance of teachers, then log in the on-line classroom using their real names. After that, students move on from individual knowledge acquisition to interpreting exercise taking, to question discussing with peers and teachers, to reflective assessment, and finally to acquire the conceptual knowledge and basic interpreting skills.

During the process, students can choose when and where to learn, and their learning is a fully interacted behavior which means that they can ask and answer questions, share their learning benefits and strategies, and make constant adjustments through reflective thinking in the flexible on-line learning environment. It is clear that a self-regulated learner is actively involved in their learning process [14]. 
Secondly, in the classroom learning, students are guided to solve the on-line problems collected by teachers, and then get fully involved in collaborative activities and interpreting skills training, such as note-taking skills, short-term memory skills, long sentence interpreting skills, etc. These student-centered activities can strengthen students' problem-solving abilities and inspire their interests to learn. That is to say, in flipped classrooms, students learn alongside their classmates in a more interactive and learner-centric educational environment [15]. Teachers, in the meanwhile, keep ongoing formative assessment of students, and adjust the activities or provide necessary help if needed, in order to maximize the in-class time by enabling students to construct their knowledge by themselves and to master the interpreting skills accordingly.

Thirdly, after the class, great emphasis is placed upon applying the interpreting skills into practice, thus to enhance the switch from skills input to skills output by the ways of simulated on-site interpretation, or relevant knowledge and skills expansion, or taking part in various interpreting examinations, such as Shanghai Advanced Interpretation, LSCAT (Language Service Competence Assessment and Training in China) Interpretation Examination.

Most importantly, through SPOC platform, teachers can furtherly enrich the resources and release supplementary tasks of different levels of difficulties to cater for students of different interpreting competence. In this way, students can find their individually suitable ways of learning, and the learning behaviors of each student are recorded, analyzed, and evaluated. After that, a Learning Evaluation Report will be given to each student, recording his weak points and strong points, and providing advices and suggestions for his further learning. This kind of after-class interactions between students and teachers is beneficial for students to optimize their learning continuously.

From the above discussion, it is found that SPOC-based flipped learning model is seamlessly connected with off-line teaching, which integrates the advantages of on-line flipped learning and off-line face-to-face teaching.

\section{Survey of Students' Reaction to the SPOC-based Flipped Learning Model}

To investigate students' reaction to the SPOC-based flipped learning model, surveys in the forms of questionnaire and face-to-face interview were conducted at the end of each semester. This survey was carried out from February to July in 2019. The research subjects were 80 students taking the interpreting course. 80 questionnaires adopted a Likert Scale were given out, and 78 were recovered, representing a participation rate of $97.5 \%$. Meanwhile, interviews were given to students, in order to know their specific ideas. The questionnaire results are shown in Table 1. 
Table 1. Students' Reaction to the SPOC-based flipped Learning Model

\begin{tabular}{|l|c|c|c|c|c|}
\hline \multicolumn{1}{|c|}{ Questions } & $\begin{array}{c}\text { Strongly } \\
\text { agree }\end{array}$ & Agree & Neutral & Disagree & $\begin{array}{l}\text { Strongly } \\
\text { disagree }\end{array}$ \\
\hline $\begin{array}{l}\text { 1. Do you agree that SPOC-based flipped learning } \\
\text { makes you easier to grasp the interpreting skills and } \\
\text { knowledge? }\end{array}$ & $\begin{array}{c}50 \\
62.5 \%\end{array}$ & $\begin{array}{c}24 \\
30 \%\end{array}$ & $\begin{array}{c}4 \\
5 \%\end{array}$ & $\begin{array}{c}2 \\
2.5 \%\end{array}$ & $\begin{array}{c}0 \\
0 \%\end{array}$ \\
\hline $\begin{array}{l}\text { 2. Does "SPOC-based flipped Learning Model" make } \\
\text { you and your teacher closer before and after the class? }\end{array}$ & $\begin{array}{c}36 \\
45 \%\end{array}$ & $\begin{array}{c}28 \\
35 \%\end{array}$ & $\begin{array}{c}12 \\
15 \%\end{array}$ & $\begin{array}{c}4 \\
5 \%\end{array}$ & $\begin{array}{c}0 \\
0 \%\end{array}$ \\
\hline $\begin{array}{l}\text { 3. Do you agree that you can learn more from an off- } \\
\text { line classroom when it is combined with SPOC-based } \\
\text { flipped learning? }\end{array}$ & $\begin{array}{c}42 \\
52.5 \%\end{array}$ & $\begin{array}{c}22 \\
27.5 \%\end{array}$ & $\begin{array}{c}10 \\
12.5 \%\end{array}$ & $\begin{array}{c}6 \\
7.5 \%\end{array}$ & 0 \\
\hline $\begin{array}{l}\text { 4. Do you think the supplementary resources and tasks } \\
\text { after class on SPOC can furtherly strengthen your } \\
\text { learning ability? }\end{array}$ & $\begin{array}{c}25 \\
31.25 \%\end{array}$ & $\begin{array}{c}45 \\
56.25 \%\end{array}$ & $\begin{array}{c}5 \\
6.25 \%\end{array}$ & $\begin{array}{c}5 \\
6.25 \%\end{array}$ & 0 \\
\hline $\begin{array}{l}\text { 5. Do you think SPOC-based flipped learning help } \\
\text { you to enhance your independent learning ability? }\end{array}$ & $\begin{array}{c}28 \\
35 \%\end{array}$ & $\begin{array}{c}40 \\
50 \%\end{array}$ & $\begin{array}{c}8 \\
10 \%\end{array}$ & $\begin{array}{c}4 \\
5 \%\end{array}$ & $\begin{array}{c}0 \\
0 \%\end{array}$ \\
\hline
\end{tabular}

From Table 1, it can be seen that there are four perspectives under investigation, i.e. on-line learning satisfaction, on-line interaction, the effect of on-line learning combined with off-line teaching, and the independent learning ability.

Firstly, question No. 1 in Table 1 is designed for the survey of on-line learning satisfaction. $62.5 \%$ strongly agree and 30\% agree that SPOC-based flipped learning does help them to grasp the interpreting skills and knowledge while only $2.5 \%$ disagree, which indicates that a majority of students have participated in the learning on SPOC platform and got a favorable outcome.

Secondly, question No. 2 is meant for the survey of on-line interaction. From Table $1,45 \%$ strongly agree and 35\% agree that "SPOC-based flipped Learning Model" can make their interaction with teachers closer before and after the class, while only $5 \%$ disagree, which suggests that the sections on SPOC platform, such as "questions and answers," "group chat", can be useful approaches for students to reach teachers before and after the class. In traditional teaching, students seldom have the chance to get help from teachers before and after the class. However, under the SPOC-based flipped learning model, students can discuss with teachers and peers on SPOC platform before and after the class whenever necessary, which really benefits students' independent learning.

Thirdly, question No. 3 is to investigate the effect of on-line learning combined with off-line teaching. From Table 1, 52.5\% strongly agree and $27.5 \%$ agree that they can learn more from an off-line classroom when it is combined with SPOC-based flipped learning. Actually, in-class time can be used to focus on some in-depth topics and enhance students' interpreting skills, since students have already had flipped learning on SPOC before the class. Furtherly, students, with an aim to solve their confusions in flipped learning before the class, are often more active in class activities, as a result, students really take their initiative to learn while teachers act as guiders in the off-line teaching.

Fourthly, questions No. 4 and No. 5 are to survey the independent learning ability and efficiency based on SPOC. From Table 1, more than $80 \%$ of the students think their independent learning ability and efficiency are enhanced through SPOC-based flipped 
learning model. The reason is that students do not blindly or aimlessly carry on their independent learning. The fact is that their independent learning is always guided and supported by teachers during the whole process. Specifically, students make their learning schedule under the guidance of teachers, acquire knowledge and skills with shared resources on SPOC, take interpreting exercises and quizzes provided by teachers, discuss with peers and teachers about some confusions, evaluate their own learning process reflectively, and receive feedbacks from teachers, then improve their learning methods and effects constantly. So, it is clear that learning is highly emphasized, and teachers only play the role of guiding students to find their suitable ways to learn. Furtherly, students with high self-efficacy tend to be optimistic and willing to learn, despite the setbacks and challenges in the learning process [16].

Besides questionnaires, one third of the students accepted a face-to-face interview which was meant to know students 'detailed ideas towards the above five questions in Table 1. The following are the main messages collected from those interviewed students.

Message 1: Conceptual knowledge is easy to grasp with shared resources on SPOC, especially the videos which can play back and forth flexibly. Questions are discussed thoroughly, and interactions increased. The skills of interpretation can be practiced in different ways.

Message 2: Teachers exert great efforts in the course, and the shared resources are abundant and useful. The self-regulated learning proposed and guided by teachers can really improve my learning efficiency.

Message 3: The on-line SPOC classroom is easily accessible and full of useful resources, which helps me to get ready in classroom activities. Classroom teaching can deepen my understanding of knowledge, and strengthen my interpreting skills.

Message 4: The classroom teaching is full of discussions and tasks, which can clarify my confusions and arouse my interest to learn, and the after-class team work is challenging but rewarding.

\section{Conclusion}

In the study, SPOC-based flipped learning model is built up to provide a flexible learning environment for students at first, then this model is seamlessly connected with off-line teaching in order to make the best out of on-line flipped learning and off-line teaching. Furtherly, in order to understand the reactions from students towards this learning model, a questionnaire, together with a face-to-face interview, was carried out at the end of each semester. From the data and interview analysis, it indicates that the SPOC-based flipped learning model helps improve the interpreting ability and efficiency of students, fosters their interest to learn, as well as activates their motivation and initiative to strengthen their learning autonomy. The main conclusions are illustrated below.

Firstly, from the perspective of teachers, in order to put students' learning at a central position, teachers need extra efforts to make preparations and teaching designs before 
the course is opened on SPOC platform, which means it is more demanding for teachers.

Secondly, the SPOC-based flipped learning model create an interactive learning environment for students, thus learning is not limited to classroom only, or confined to individual learning only. Meanwhile, through the model, teachers can supervise and evaluate students' learning habits and effects during the whole process, which, in return, enables teachers to improve their teaching design constantly.

Thirdly, from the perspective of students, learning is more challenging but rewarding. Instead of receiving knowledge passively from teachers in a traditional class, students have to make learning schedule by themselves, and proceed with individual learning and collaborative learning to clarify their confusions, and to enhance their interpreting knowledge and skills initiatively. In this way, students change from passive learning to active learning, and their learning becomes flexible, diversified, and individualized.

Fourthly, through SPOC platform, teachers can constantly update sharing resources and make adjustments of teaching design according to the feedbacks and questions collected from the flipped learning before the class. Moreover, after the class, supplementary tasks of different level of difficulties are designed for students of different interpreting competence, which means that it is really possible to offer an individually suitable guidance for each student.

\section{Acknowledgement}

This study was supported by the Zhejiang Provincial Project of China "On the Translation and Transmission of Chinese Cultural Key Words from the Perspective of Variation Theory" (Y201942343) and the Zhejiang Provincial Teaching Reform Project of China (jg20180265).

\section{$7 \quad$ References}

[1] Johnson, L. et al. (2013). The NMC Horizon Report 2013. Austin, Texas: The New Media Consortium.

[2] Wang, J. N. (2018). Studying on Interpreting Teaching with Blended Learning Model Based on Flipped Classroom. Journal of North China University of Science and Technology (Social Science Edition), 18(4),105-112.

[3] Wang, H. L. (2019). An Action Research on Deep Flipped Interpreting Learning. Foreign Language Education in China, 2(1), 73-78.

[4] Wang, H. S., Yang, C. S. (2019). Interpreting Technologies in the Era of Artificial Intelligence: Concepts, Influences and Trends. Chinese Translators Journal, 40(6), 69-79.

[5] Sams, A., Bergmann, J. (2013). Flip your Students' Learning. Educational Leadership, 70(6), 16-20.

[6] Flipped Learning Network. The Four Pillars of F-L-I-PTM. retrieved from https://flipped learning.org/definition-of-flipped-learning/

[7] Gao, X. B. (2018). Effect of SPOC Flipped Classroom Learning Based on MOOC Platform. Advances in Social Science, Education and Humanities Research, 89 (4), 225-231. 
[8] Shi, H.B., Liu, M., Zhu, Z.H., et al. (2018). Research on the Learning Willingness of Engineering College Students in SPOC Flipped Class. Advances in Social Science, Education and Humanities Research, 220 (3), 51-57. https://doi.org/10.2991/iceemt-18.2018.11

[9] Lundin, M., Rensfeldt, A.B., Hillman, T., et al. (2018). Higher education dominance and siloed knowledge: a systematic review of flipped classroom research. International Journal of Educational Technology in Higher Education, 15(20),1-30. https://doi.org/10.1186/s41239-018-0101-6

[10] Chen, J., Wu, Q. (2019). IT-Assisted Interpreter Training in Retrospect and Prospect. Chinese Translators Journal, 40(2), 68-78.

[11] Kim, D. (2017). Flipped Interpreting Classroom: Flipping Approaches, Student Perceptions and Design Considerations. The Interpreter and Translator Trainer, 11(1), 38-55. https://doi.org/10.1080/1750399x.2016.1198180

[12] Jonassen, D., Howland, J., Moore, J., et al. (2003). Learning to Solve Problems with Technology. Englewood Cliffs, NJ: Prentice Hall.

[13] El, M. Y. (2019). Flipped Learning. In: Rheumatology Teaching. Springer, Cham. pp. 285303. https://doi.org/10.1007/978-3-319-98213-7_15

[14] Nordin, H., Hashim, R. A. (2020). Online Self-Regulated Learning Strategies in MOOCs: A Measurement Model. International Journal of Emerging Technologies in Learning, 15(8), 255-263. https://doi.org/10.3991/ijet.v15i08.12401

[15] Wang, K., Zhu, C. (2019). MOOC-based flipped learning in higher education: students' participation, experience and learning performance. International Journal of Educational Technology in Higher Education, 16(33), 1-18. https://doi.org/10.1186/s41239-019-0163-0

[16] Chen,Y. C. (2020). Correlation between Self-Efficacy and English Performance. International Journal of Emerging Technologies in Learning, 15(8), 223-234. https://doi.org/10.39 91/ijet.v15i08.13697

\section{Author}

Juan Chen is a Teacher of the Foreign Languages College, Zhejiang Wanli University, Ningbo, 315100 China. Her research interests include interpreting teaching and internet-based teaching. (wmjcj@163.com)

Article submitted 2020-04-02. Resubmitted 2020-05-07. Final acceptance 2020-05-07. Final version published as submitted by the author. 